\title{
A Modular Car Body for Sustainable, Cost-Effective, and Versatile Vehicle Development
}

\author{
Christoph Hartmann ${ }^{1, *}$ (D), Markus Welm ${ }^{1}$ (D), Sven Schreyer ${ }^{1}$, Christoph Hartmann ${ }^{2}$ (D) and Wolfram Volk ${ }^{1,2}$ \\ 1 Chair of Metal Forming and Casting, Technical University of Munich, Walther-Meissner-Strasse 4, \\ 85748 Garching, Germany; markus.welm@utg.de (M.W.); info@utg.de (S.S.); wolfram.volk@utg.de (W.V.) \\ 2 Fraunhofer Research Institution for Casting, Composite and Processing Technology IGCV, Zeppelinstrasse 15, \\ 85748 Garching, Germany; info@igcv.fraunhofer.de \\ * Correspondence: christoph.hartmann@utg.de; Tel.: +49-89-289-13769
}

\section{check for}

updates

Citation: Hartmann, C.; Welm, M.; Schreyer, S.; Hartmann, C.; Volk, W. A Modular Car Body for Sustainable, Cost-Effective, and Versatile Vehicle Development. Technologies 2021, 9, 13. https://doi.org/10.3390/ technologies 9010013

Received: 10 November 2020

Accepted: 2 February 2021

Published: 9 February 2021

Publisher's Note: MDPI stays neutral with regard to jurisdictional claims in published maps and institutional affiliations.

Copyright: (C) 2021 by the authors. Licensee MDPI, Basel, Switzerland. This article is an open access article distributed under the terms and conditions of the Creative Commons Attribution (CC BY) license (https:// creativecommons.org/licenses/by/ $4.0 /)$.

\begin{abstract}
Availability, sustainability, and functionality pose particular challenges for the value chain of individual mobility. Therefore, in this work, the typical value chain is broken up and the traditional approaches are extended with an open-source perspective. The focus is on modularity and simplicity in order to enable the broadest possible applicability and fast implementation of local production. Nevertheless, the mobility concept should meet the current standards, especially with regard to safety. A modular vehicle frame is presented as a basis, which meets all regulations, can be built in self-assembly, and is available as open-source.
\end{abstract}

Keywords: car body; space frame; modular design; self-assembly; local production

\section{Introduction}

Individual mobility is a big challenge for today's world in terms of availability, sustainability, and functionality [1,2]. Especially with regard to demographic growth in regions with only limited infrastructure, the transportation of goods and people is a major issue. However, global automotive industry mainly bases on markets with important purchasing power and large lot sizes [3-5]. Structurally weak regions are often left out in this context, despite the fact that mobility is a fundamental precondition for progress and improvement. A promising concept for those areas must meet the specific market requirements of each region and consider the locally available resources. Therefore, a flexible, easy, and cost-effective open source platform is ideal for incorporating local circumstances and possibilities. In this way, unconventional materials could be used for example, which suit prevailing climate and infrastructure conditions better and are easier to procure and process than materials commonly used in automotive industry. Further, open-source approaches offers decentralized, hence, international and interdisciplinary, development across borders that drives global digitization.

The basis of any vehicle is a frame supporting the chassis, the drivetrain, as well as the passenger and cargo compartment [6]. Consequently, when designing a flexible vehicle concept, the frame and car body are key issues. Chassis, drive train, and the passenger and cargo compartment can be adapted according to each area of application. If possible, the production of the components and assembly should be relocated to the target region, whereby the manufacturing requirements must be met. On the one hand, due to the lower wages, the manufacturing costs and thus also the price of the vehicle are lowered. On the other hand, this supports local economy and existing industry. Therefore, the applied manufacturing technologies only need low initial invest when compared to the established high batch and high automated manufacturing system known from automobile industry, which enables fast implementation. The used production processes are straightforward scalable and, hence, even allow an economic medium batch size production. In addition, know-how is established for maintenance of the components and the vehicle. The aim of 
the presented modular car body is to provide a platform for local, cost-effective vehicles that are tailored for each specific region with a high amount of local added value.

\section{Brief State of the Art}

Modern car bodies meet manifold requirements reaching from aesthetics over lightweight design to passenger safety and low manufacturing costs [7-9]. Beside different small batch variants, two main types of architecture can be differentiated: self-supporting shell design and space frame design [10]. A typical space frame structure uses profile-shaped components and knot elements in order to provide a supporting framework. Complement components, like planking parts, for example, make no significant contribution to the structural behavior the car body. In contrast, a self-supporting shell design combines the supporting structure and other components of the car body. Therefore, sheet metal parts are nested together to achieve a suitable overall structure [10].

Efficient and economic manufacturing of sheet metal shells is only possible for large lot-sizes, since the investment for the tool sets, forming presses, assembly lines, and peripheral facilities must pay off through the amount of the produced parts [11], despite different approaches for small batch sheet metal processing [12,13]. The high initial investment may be also seen as a core reason that rules local production out. Hence, local, flexible, and individualized car body manufacturing is hardly possible using shell-design [14,15]. Because of this, in utility vehicle design space frame or ladder frame concepts are utilized [16]. Space frame structures are commonly made of extruded profiles and casted knots of aluminum [17,18], but also material mix concepts are possible [19]. In this way, lightweight and safety aims are met. The assembly and joining of the space frame components needs special attention due to the constraints of the manufacturing processes used [20,21]. This holds true for highly automated batch assembly as well as manual production. Even today's car kits, like from Lotus, Caterham, or Pilgrim, for example, are supplied with ready mounted frames for complexity reasons. However, using building kits saves costs for the assembly and opens room for customization and individualization.

In this work, an open car body building kit is presented taking up the idea of selfassembly for the space frame structure. In this way, a cost-effective and modular platform for region specific mobility is provided [22]. All of the employed manufacturing techniques only afford low initial invest and hence, enable to build up a local, decentralized production that respects the open-source character.

\section{Modular Car Body Design}

When designing a modular frame structure, various requirements must be considered. The basic function of the car body structure is to distribute operating loads, which are primarily initiated by the front axle and rear axle carriers and to ensure passive occupant protection in the event of an accident. However, package requirements, but also costeffective production of components, must be considered. In addition, there are numerous customer-driven criteria, such as design or comfort requirements in terms of torsional and bending stiffness. The basis of the modular car body is a ladder frame, which is commonly used for utility vehicles because of its flexibility and versatility. It consists of longitudinal and transverse girders and accommodates the superstructures, such as the passenger compartment and cargo module, in addition to chassis and powertrain.

The materials used are standardized metal profiles and individually adapted casting knots of a simple alloy. Fiber reinforced plastics are deliberately not consulted for cost, availability, maintenance, servicing, and manufacturing reasons. Hence, the total costs for the material used for the car body prototype sum up to only 1600 Euro. In order to allow for off-road use, the frame provides a high spring travel and sufficient torsional elasticity combined with high bending stiffness to support heavy loads. Therefore, Uprofiles are used for the longitudinal girders. Standing mounting structures allow for the simple connection of suspension components. The profiles have openings in the inner direction, which allows for initiating suspension forces near the shear center. The 
cross members were also designed as open profiles, which, on the one hand, enables the control torsional stiffness and, on the other hand, offers a cost-effective production by means of cutting and bending with the required design flexibility. Structural steel (S235JR) with a thickness of $3 \mathrm{~mm}$ was used for the majority of the frame structure and of 5-6 mm for heavily loaded components, such as the chassis connections. In order to ensure stiffness requirements reinforcements are implemented on the longitudinal girders at the height of the passenger compartment, stiffening brackets between longitudinal and transverse girders and a stiffening plate in the bottom area, which, for example, could be used as battery tray without additional components in the case of a hybrid or electrical vehicle concept.

The passenger compartment is built up using round profiles due to their homogeneous bending stiffness independent of stress direction. Through a rigid connection to the ladder frame base, the substructure also contributes to the stability and stiffness of the car body. For the purposes of lightweight design, aluminum round profiles with an outer diameter of $48 \mathrm{~mm}$ and a wall thickness of $5 \mathrm{~mm}$ are mainly used. In accordance with the respective load scenarios, specific parts, such as the side entry rails, for example, are made of steel with a smaller outer diameter of $27 \mathrm{~mm}$ and a wall thickness of $2 \mathrm{~mm}$. Individually designed aluminum casting knots (see Section 4) allow for the use of simple straight profiles and, hence, an economical manufacturing and easy assembly. Furthermore, great design freedom and flexibility is preserved. As an example for the integral design possibilities, handles are integrated in the casting knots at the top of the A-pillar. Figure 1 shows the whole car body frame geometry created with CATIA V5, Dassault Systems, Velizy-Villacoublay, France.
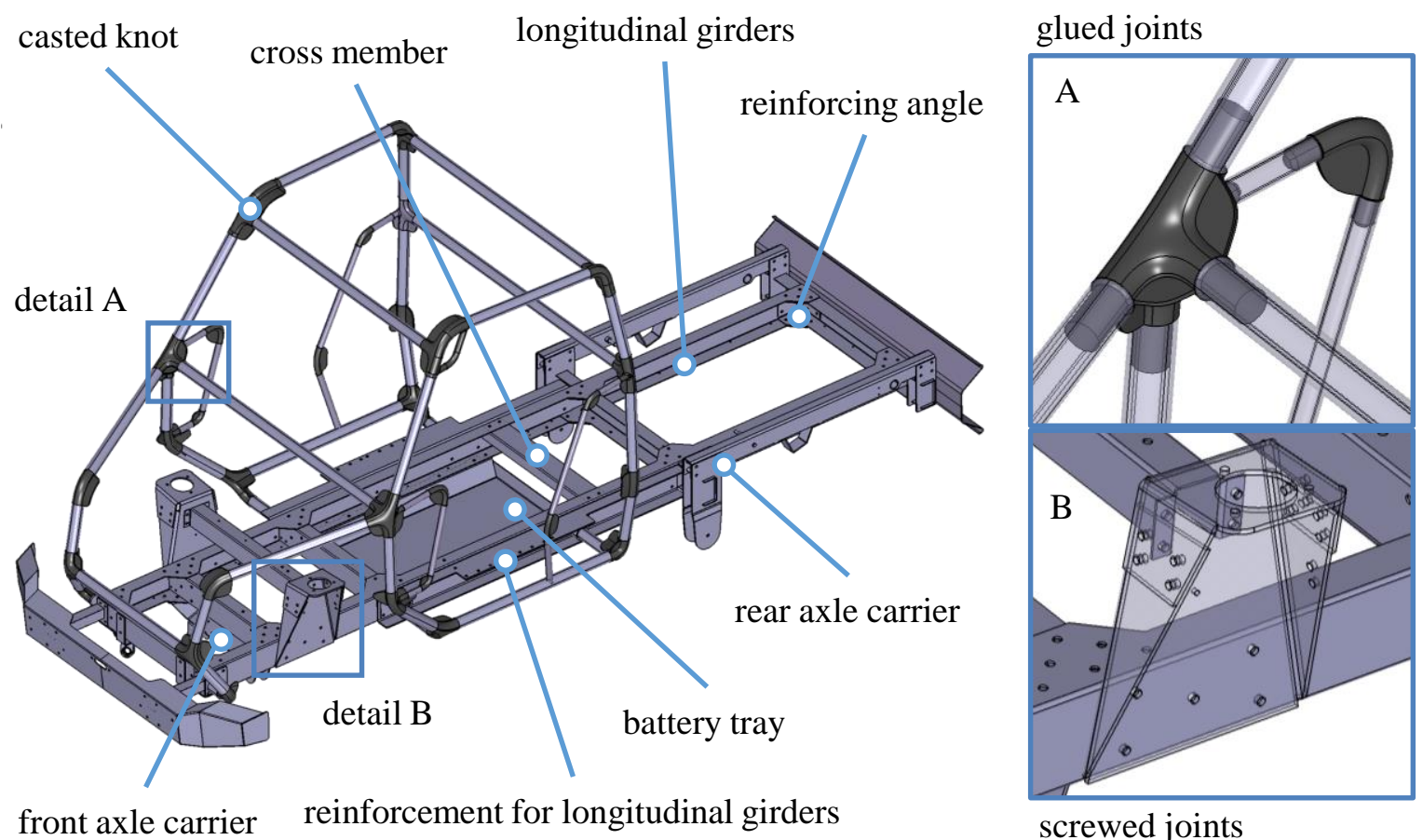

front axle carrier reinforcement for longitudinal girders

screwed joints

Figure 1. Design of the ladder frame with two joint details (data set may be downloaded from [22]).

The properties of the car body are in accordance with the class EG/EU type-approval L7e, where 29 requirements regarding, for example, active and passive safety, must be met. On the one hand, a maximum empty weight of $600 \mathrm{~kg}$ is permitted, which is also a reason for lightweight design. The car body frame, as depicted in Figure 1, weighs $230 \mathrm{~kg}$ in total, leaving enough room for any kind of attachment parts. The dimensions of the vehicle are limited to a length of $3700 \mathrm{~mm}$, width of $1500 \mathrm{~mm}$, and height of $2500 \mathrm{~mm}$, which are reached by the flexible design and package. The passenger compartment must be closed 
and separated from the cargo area by a partition. With regard to crash regulations, no test load cases are prescribed in this class, which is why the tests provided in related vehicle classes are used to safeguard the function of the supporting structure. Section 6 describes these in detail.

\section{Aluminum Cast Knots}

For the connection between the tubes, casted aluminum knots were developed. Casting parts are ideally suited for the joints because of their almost unlimited freedom of design. Furthermore, it was possible to implement technical functionalities into the geometry without additional cost. The manufacturing process of the indirect additive manufacturing was chosen to produce the casting parts. In this procedure, sand molds are manufactured via a binder jetting process and they are subsequently used for casting. The additive manufactured molds were made of silica sand and an organic binder, and they were kindly supplied by Voxeljet AG, Friedberg, Germany. They were used in a gravity casting at MWS Garching GmbH, Garching, Germany, and mechanically processed. Through the indirect additive manufacturing process, high manufacturing costs caused by model making and mold design were avoided. Especially for low to medium quantities, this process is profitable. In the upper row, Figure 2 shows two printed molds out of silica sand and an organic binder. It can be seen that the two mold parts are mirrored for the left, respectively, right side of the vehicle structure.

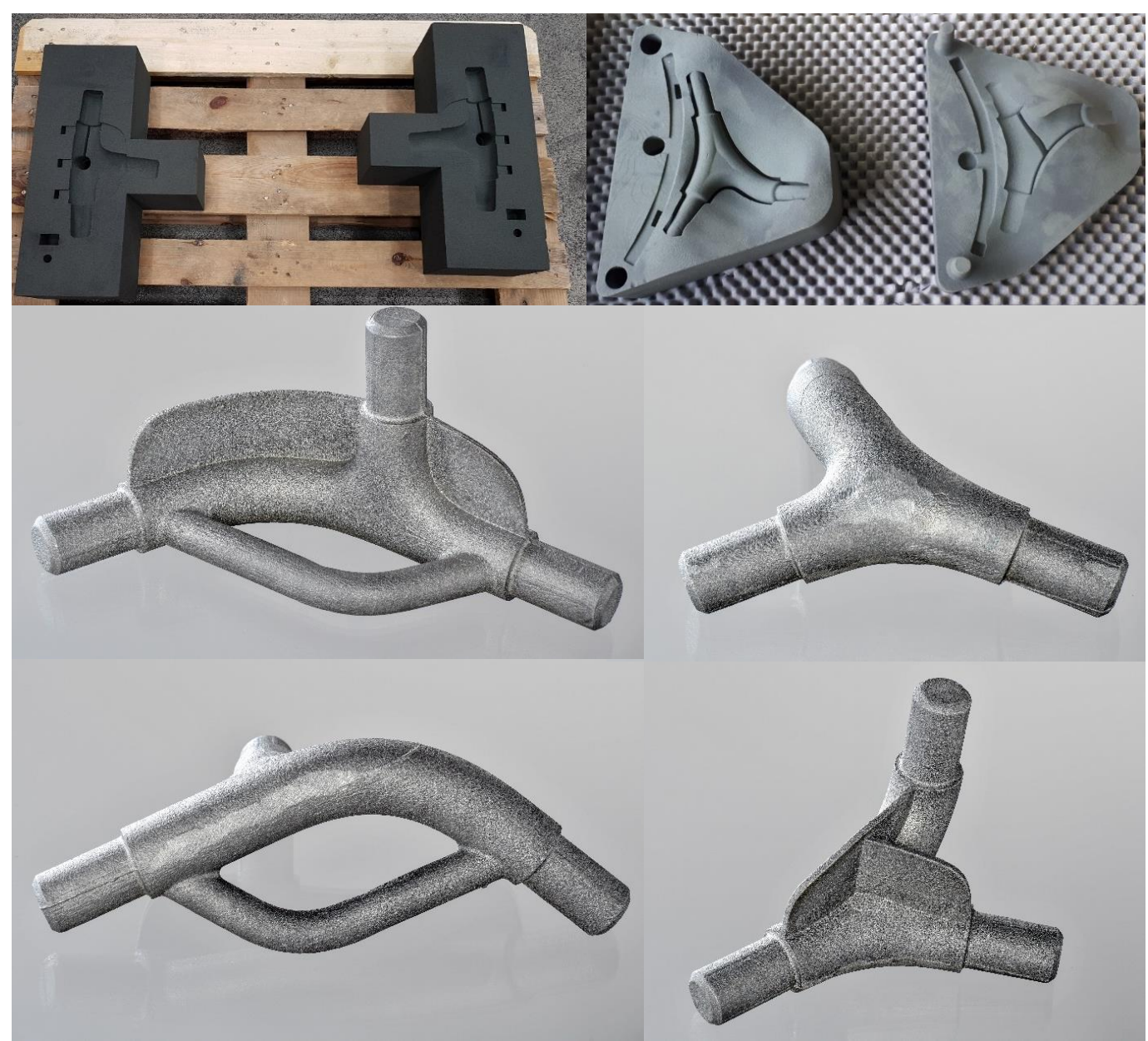

Figure 2. The upper row shows two printed mold parts fort manufacturing the casting knots. The molds are mirrored to be used in the left and right side of the vehicle body structure. The lower rows present two sample functionally integrated casted knots for joining the tubes of the vehicle body. The passenger can use the additional strut (left knot) as a handle. The reinforcements of the left knot are the fixing points for the roof cladding and windscreen. The right knot joins the tubes at the cars entry. 
After casting and removing the casting system, the knots are finished for assembly. In the lower rows, Figure 2 shows casted knots and the advantages of the indirect additive manufacturing by integrating passenger features into the part itself. For example, the additional strut was integrated into the part for the passenger to be used as a handle. This avoids an additional assembly process. The flat reinforcements increase the stiffness of the structure in the case of an accident, but they are also used as fixations points. The roof cladding and the windscreen are screwed right into the casting knot. This functional integration is not raising the costs of the part due to the adaptable manufacturing process. A holistic approach to the whole manufacturing process lowers the time from delivering the $\mathrm{CAD}$ data to the suppliers until receiving the mechanically processed casting knots for the assembly.

In order to design the casting process in a robust way for each knot, numerical analysis was carried out using the software Magma 5.4, Aachen, Germany. The upper row in Figure 3 shows the porosity results as well as the internal stress distribution at final ambient temperature after casting and cooling. Pores occur only in the risers and the part remains free of pores. This has been validated using $x$-ray analysis, see the lower rows of Figure 3. The internal stresses show a maximum of around $50 \mathrm{MPa}$ that is far below the yield limit of the aluminum alloy. Hence, it is meaningful to neglect them for the structural analysis of the car body in Section 6.

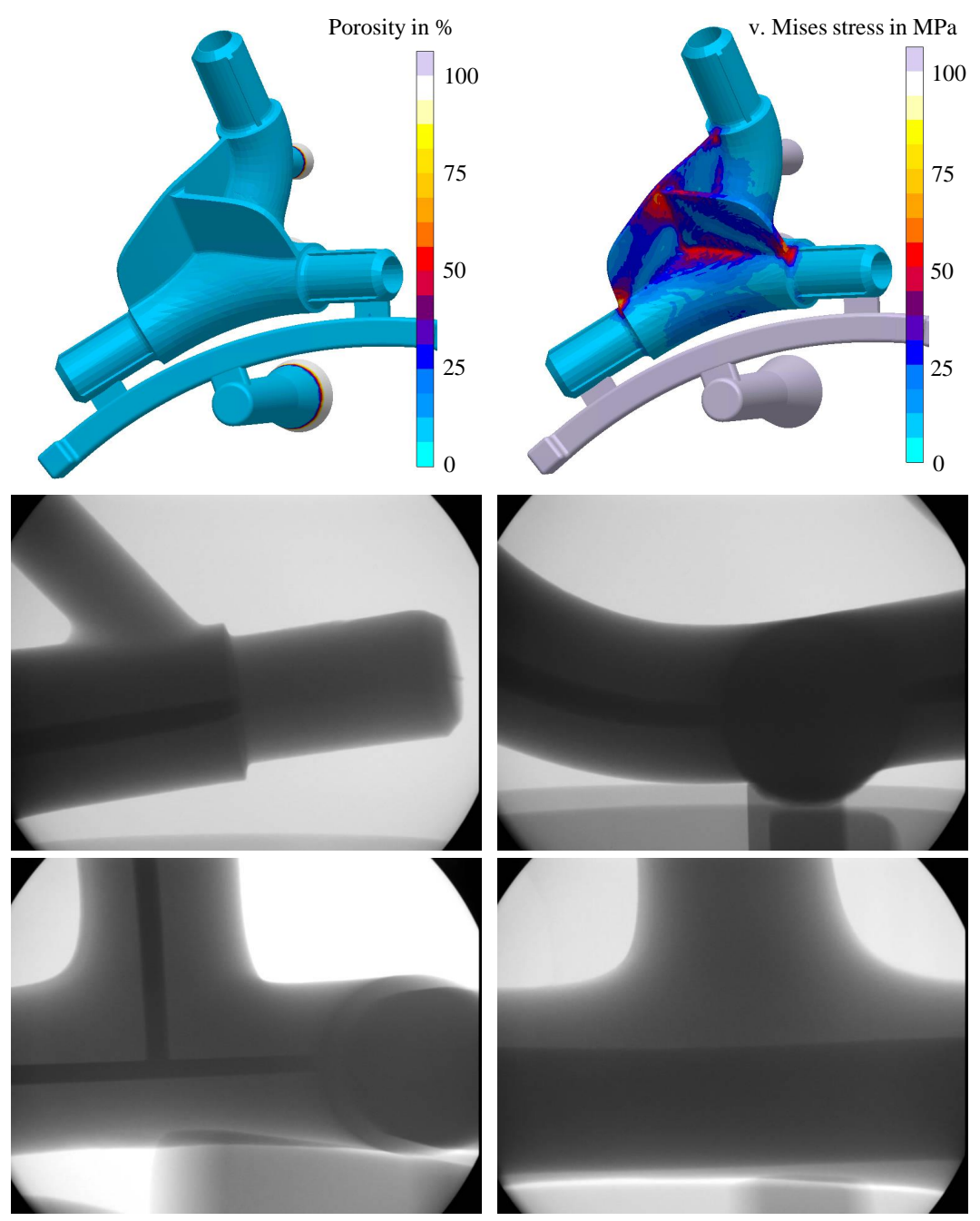

Figure 3. The upper row shows the numerical analysis of the casting process and residual stresses of a sample knot. The lower rows presents the results of $X$-ray measurements of a sample knot in order to control for pores in the material. 


\section{Cargo Module}

One of the basic ideas of the open source modular car body is to enhance utility by a modular construction, particularly with regard to the loading platform. Therefore, various platforms for farmers, medics, or other village inhabitants exists. The top modules have three important main tasks: Improving economic power, increasing mobility, and enhancing medical supply. All of these steps make a reduction of the rural exodus possible. The improvement of the economic independence of the rural population has great significance in the loading platform design. Agricultural work mainly determines the economic power of those people. Hence, the open source modular car body has to especially support fieldwork. For this purpose, there are some devices, like a tiltable bed, for the transportation of agricultural goods from the fields to the village or to markets in bigger cities. Another one is for people transportation, e.g., workers to the fields, but also for schoolchildren to school. This leads to the second big goal: raising the mobility and range of village inhabitants which is a key factor to provide them access to the bigger cities with schools, markets, and medical supply [23]. Another possibility to make health care available is to bring medics and medical equipment to the rural population. To fit all of those tasks, the open source modular car body is equipped with a tool-free quick release and mounting system for a fast change of different loading modules.

Even in South Africa, as in most parts developed country, the average number of visits to medical facilities is 2.5; in Germany, it is 9.9 [24]. Because of this, it is necessary to bring the doctor, the medical equipment, and the medicine to the people. The development process of a loading platform for fast medical supply is described hereinafter. The platform should combine a doctor's office and mobile pharmacy.

The main objective was to reach a high functionality and durability with limited financial and production resources. Manufacturing with regional resources takes place in Sub-Saharan Africa to ensure reasonable production costs and provide the local creation of value. The most important demands to the manufacturing technologies are low costs for tools and workmanship, as well as slight claims to precision. Hence, the chosen production techniques are sawing for separation of material and screwing as well as welding for connecting. The used materials are wood and a S235JR steel, which are cheap and easy to process. Furthermore, the S235JR steel provides good weldability. In consideration of the above-mentioned parameters, the platform is a grid frame construction with equal square profiles, being covered by laminated wood panels. The advantage of the laminated panels in comparison to solid wood is the lower capillary-porous water uptake.

To enable a medic to supply satisfying medical care to the rural population, there is a need for indispensable special equipment, like a fridge, cabinet, water tanks, electricity, weather protection, and light. Moreover, the loading module should be lockable to prevent the utensils from larceny. A $12 \mathrm{~V}$ wiring system with connection to the open source modular car body battery provides electrical energy. It powers a medical fridge, which has a certification for the transportation of human tissue and medical compunds, as well as the light system and a water pump. The square profiles serve as cable ducts and protect the electric wires against humidity and mechanical impact. Two telescopic canopies deploy the weather protection of equipment and persons. After the decision regarding the platform concept considerations of restricted installation space, electric interfaces and location of the center of gravity are necessary.

\section{Safety of Passengers}

The basic function of the bodywork structure is to accommodate the working load and ensure the passive passenger protection in the case of an incident. The front and the rear axle beam are the main parts for the force transmission into the chassis. Package requirements and an economic manufacturability affect the constructive design. Furthermore, there is an influence to, e.g., bending and torsion stiffness by customer-oriented criteria like driving comfort. The body is a ladder frame construction, usually used in commercial 
vehicles, which is the basic structure for the suspension and the powertrain. It additionally takes the passenger compartment and loading module.

The ladder frame consists of open longitudinal and transversal beams, which allows for an economic manufacturing with usage of laser cutting and folding. The torsion elasticity of those open profiles, in contrast to closed profiles, contributes to a reduction of the spring deflections. Te passenger compartment consist of aluminum tubes connected by aluminum cast knots, as mentioned above. The centric arranged battery case helps to reach a higher frame stiffness without the use of additional elements. Crash boxes mount the front bumper to the ladder frame to absorb the energy of a frontal impact. The package requirements and lower crash demands reasons for a direct screwing of the rear bumper to the frame. For verification of the functionality, the finite element model considers all of the above-mentioned parts.

The use of shell elements (Belytschko-Tsay type) enables an efficient calculation of the occurring forces and deformations. Therefore, the creation of middle planes and simplification of parts are expedient. The closing of boring holes and the neglecting of bending radii and chamfers enhances the quality and reduces the amount of elements. Common knots represent welded connections. Displacement boundary conditions realize the modeling of screw and bond connections. The upper picture presented in Figure 4 shows the frame finite element model built with the preprocessor HyperMesh, Altair, Troy, United States. In total, the frame is modeled by approximately 110,000 finite elements. The finite element model helps to verify the functionality of the frame under different load spectra. This includes normative regulated load conditions, like the steadiness of the roof in the case of a rollover [25].

The lower left picture shown in Figure 4 exemplary shows the determination of the torsion stiffness with the LS-DYNA simulation software, DYNAmore GmbH, Stuttgart, Germany. Here, the von Mises equivalent stress is plotted to obtain an impression of the loading conditions inside the frame. The locking of the translational degrees of freedom represents the frame mounting. The application of an areal testing force of $\pm 5000 \mathrm{~N}$ in a vertical direction causes a torsional moment. The output is an intermediate displacement of $-4.51 \mathrm{~mm}$ in negative and $+4.35 \mathrm{~mm}$ in positive force direction. Accordingly, the torsion stiffness is $7576 \mathrm{Nm} /{ }^{\circ}$, which exceeds the required minimum stiffness of $6000 \mathrm{Nm} /{ }^{\circ}$ with adequate guaranty.

The lower right picture presented in Figure 4 shows the results for the determination of the bending stiffness. Again, the frame mountings represent the fixed support. A force of $50 \mathrm{kN}$ was applied symmetrically on both longitudinal members. The bending stiffness computes to $6328 \mathrm{~N} / \mathrm{mm}$, which also exceeds the required minimum stiffness $(6000 \mathrm{~N} / \mathrm{mm})$. The maximum stresses in the ladder frame increase up to $240 \mathrm{MPa}$ that lie below the yield limit of the used material. 


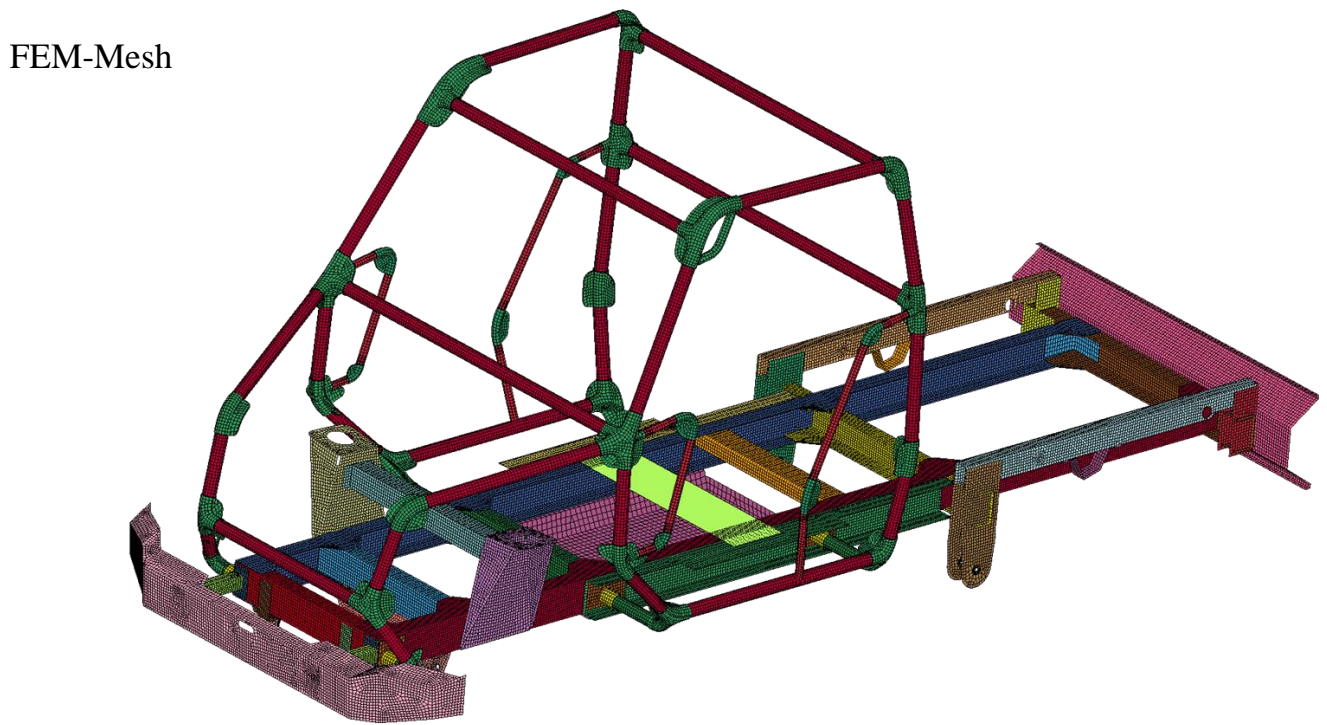

v. Mises stress in $\mathrm{MPa}$

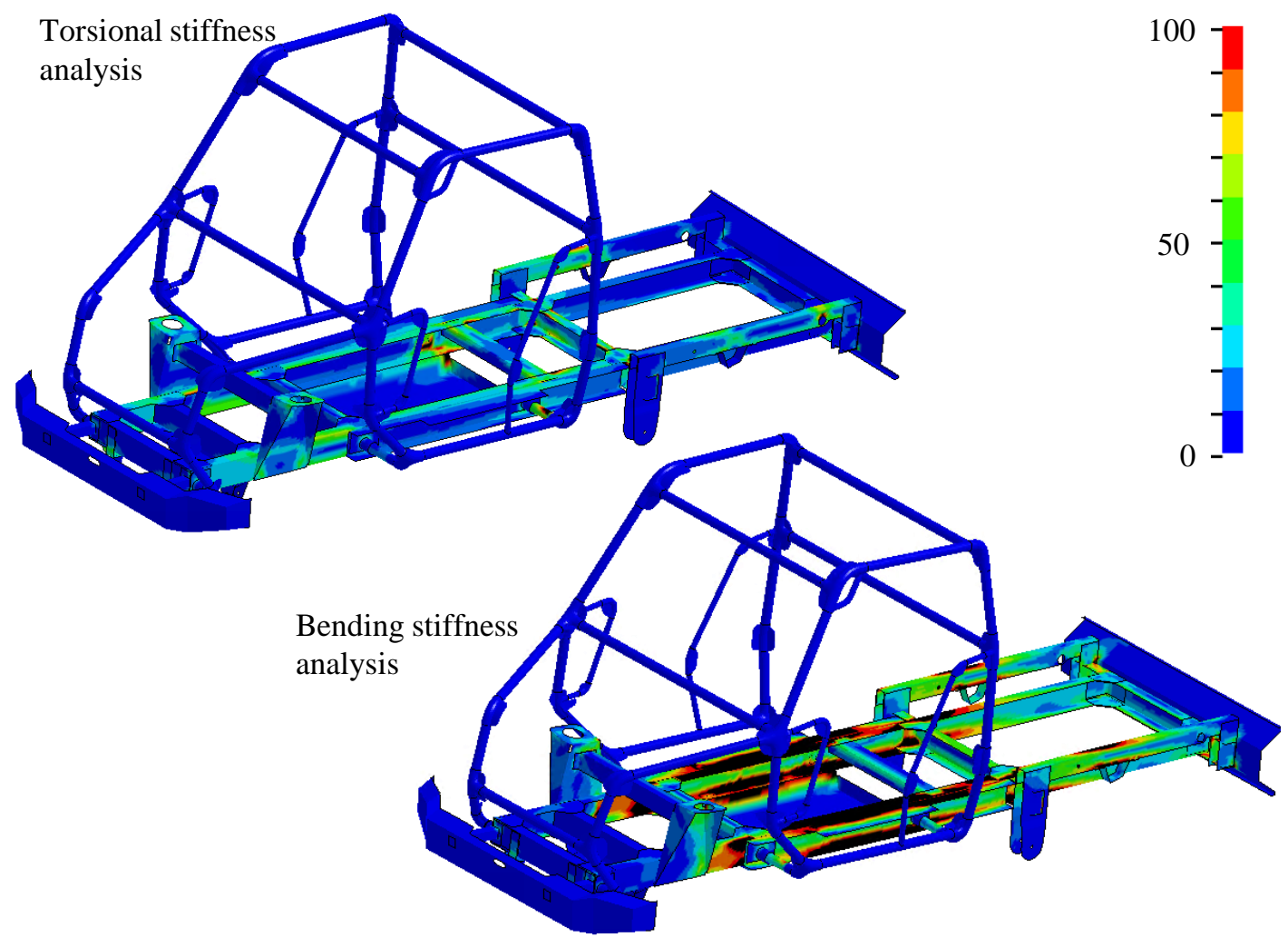

Figure 4. Finite element modeling (top), determination of torsional stiffness (lower left) with an applied load of $\pm 5000 \mathrm{~N}$ in vertical direction, and determination of bending stiffness (lower right) with an applied load of $\pm 50,000 \mathrm{~N}$ as examples for the conducted numerical tests.

\section{Conclusions}

The car concept that is considered in this article provides high degrees of sustainability on manifold levels throughout the whole value chain. During the development process, the simplicity of the construction received special attention. This enables car part production in the target regions and, thus, significantly less transportation costs and environment impacts hand-in-hand with low initial investment. Furthermore, it enhances local added value in development regions. Another influencing factor in sustainability in a car life is maintenance and service work, which can be executed by the car users themselves, due to the ease of 
construction and use of materials that are locally available. With the modular space-frame concept, the car can be used for various applications, like fieldwork, people transportation, or medical supplies. This helps rural citizens in developing counties to enhance their wealth, the quality of medical care, and especially the level of education. Consequently, this car concept helps to improve the economic status in development countries.

Author Contributions: Conceptualization, C.H. ${ }^{1}$ and M.W.; methodology, C.H. ${ }^{1}$; software, C.H. ${ }^{1}$; validation, C.H. ${ }^{1}$ and M.W.; formal analysis, C.H. ${ }^{1}$; investigation, C.H. ${ }^{1}$, M.W., S.S. and C.H. ${ }^{2}$; resources C.H. ${ }^{1}$ and M.W.; data curation C.H. ${ }^{1}$; writing-original draft preparation, C.H. ${ }^{1}$ and M.W.; writing-review and editing, C.H. ${ }^{1}$, M.W. and W.V.; visualization, C.H. ${ }^{1}$, M.W., S.S. and C.H. ${ }^{2}$; supervision, W.V.; project administration C.H. ${ }^{1}$ and M.W.; funding acquisition W.V. ${ }^{1}$. All authors have read and agreed to the published version of the manuscript.

Funding: This research was supported by the Bayerische Forschungsstiftung (BFS).

Institutional Review Board Statement: Not applicable.

Informed Consent Statement: Not applicable.

Data Availability Statement: The data presented in this study are openly available in zenodo at https://doi.org/10.5281/zenodo.4084936, see [22].

Conflicts of Interest: The authors declare no conflict of interest.

\section{References}

1. Duddeck, F. Multidisciplinary optimization of car bodies. Struct. Multidiscip. Optim. 2008, 35, 375-389. [CrossRef]

2. Sheller, M. Automotive Emotions. Theory Cult. Soc. 2004, 21, 221-242. [CrossRef]

3. Wells, P.; Rawlinson, M. The New European Automobile Industry; Palgrave Macmillan UK: London, UK, 1994. [CrossRef]

4. Roth, R.; Clark, J.; Kelkar, A. Automobile bodies: Can aluminum be an economical alternative to steel? JOM 2001, 53, 28-32. [CrossRef]

5. Wozniak, L.; Clements, P. How automotive engineering is taking product line engineering to the extreme. In Proceedings of the 19th International Conference on Software Product Line, SPLC 2015, Nashville, TN, USA, 20-24 July 2015; Schmidt, D.C., Ed.; ACM Press: New York, NY, USA, 2015; pp. 327-336. [CrossRef]

6. Reif, K. Fundamentals of Automotive and Engine Technology; Springer Fachmedien Wiesbaden: Wiesbaden, Germany, 2014. [CrossRef]

7. Happian-Smith, J. Introduction to Modern Vehicle Design; Elsevier Science: Burlington, MA, USA, 2001.

8. Walker, G.; Stanton, N.; Young, M. The ironies of vehicle feedback in car design. Ergonomics 2006, 49, 161-179. [CrossRef] [PubMed]

9. Hyun, K.; Lee, J.H.; Kim, M. The gap between design intent and user response: identifying typical and novel car design elements among car brands for evaluating visual significance. J. Intell. Manuf. 2017, 28, 1729-1741. [CrossRef]

10. Birkert, A.; Haage, S.; Straub, M. Umformtechnische Herstellung Komplexer Karosserieteile; Springer: Berlin/Heidelberg, Germany, 2013. [CrossRef]

11. Siegert, K.; Altan, T.; Nakagawa, T. Development and Manufacture of Dies for Car Body Production. CIRP Ann. 1997, 46, 535-543. [CrossRef]

12. Hartmann, C.; Volk, W. Knowledge-based incremental sheet metal free-forming using probabilistic density functions and voronoi partitioning. Procedia Manuf. 2019, 29, 4-11. [CrossRef]

13. Hartmann, C.; Volk, W. An artificial neural network approach for tool path generation in incremental sheet metal free-forming. J. Intell. Manuf. 2019, 29, 757-770. [CrossRef]

14. Patchong, A.; Lemoine, T.; Kern, G. Improving Car Body Production at PSA Peugeot Citroën. Interfaces 2003, 33, 36-49. [CrossRef]

15. Nieuwenhuis, P.; Wells, P. The all-steel body as a cornerstone to the foundations of the mass production car industry. Ind. Corp. Chang. 2007, 16, 183-211. [CrossRef]

16. Hoelzle, J.; Amrhyn, O.; McAlexander, G. (Eds.) Utility Vehicle Design Handbook, 2nd ed.; Society of Automotive Engineers: Warrendale, PA, USA, 1991; Volume 16.

17. Both, J.; Brüggemann, T.; Dosch, S.; Elser, J.; Kronthaler, M.; Morasch, A.; Otter, M.; Pietzka, D.; Selvaggio, A.; Weddeling, C.; et al. Advanced manufacturing and design techniques for lightweight structures. Int. Alum. J. 2011, 87, 60-64.

18. Hirsch, J. Aluminium in Innovative Light-Weight Car Design. Mater. Trans. 2011, 52, 818-824. [CrossRef]

19. Kleiner, M.; Tekkaya, A.; Becker, D.; Pietzka, D.; Schikorra, M. Combination of curved profile extrusion and composite extrusion for increased lightweight properties. Prod. Eng. 2009, 3, 63-68. [CrossRef]

20. Liedl, G.; Bielak, R.; Ivanova, J.; Enzinger, N.; Figner, G.; Bruckner, J.; Pasic, H.; Pudar, M.; Hampel, S. Joining of Aluminum and Steel in Car Body Manufacturing. Phys. Procedia 2011, 12, 150-156. [CrossRef]

21. Fleischer, J.; Otter, M.; Beuke, F. Method to compensate production related deviations for the assembly of space-frame-structures. Prod. Eng. 2014, 8, 207-216. [CrossRef] 
22. Hartmann, C.; Welm, M.; Schreyer, S.; Hartmann, C.; Volk, W. A Modular Car Body for Sustainable, Cost-Effective, and Versatile Vehicle Development. Technologies 2021, 9, 13. [CrossRef]

23. Cooper, A.; Kirton, J.; List, F.; Besada, H. Africa's Health Challenges: Sovereignty; Routledge: London, UK, 2013. [CrossRef]

24. OECD. Doctors' Consultations (Indicator); OECD: Paris, France, 2020. [CrossRef]

25. National Highway Traffic Safety Administration (NHTSA). Federal Motor Vehicle Safety Standards (82 FR 3854); NHTSA: Washington, DC, USA, 2017. 